Article

\title{
Development of an Automated Method for Selected Aromas of Red Wines from Cold-Hardy Grapes Using Solid-Phase Microextraction and Gas Chromatography-Mass Spectrometry-Olfactometry
}

\author{
Lingshuang Cai ${ }^{1,2}$, Somchai Rice ${ }^{1,3}$, Jacek A. Koziel ${ }^{1,3,4, *(D)}$ and Murlidhar Dharmadhikari ${ }^{4}$ \\ 1 Department of Agricultural and Biosystems Engineering, Iowa State University, Ames, IA 50011, USA; \\ Lingshuang.Cai@dupont.com (L.C.); somchai@iastate.edu (S.R.) \\ 2 DuPont Crop Protection, Stine-Haskell Research Center, Newark, DE 19711, USA \\ 3 Interdepartmental Toxicology Graduate Program, Iowa State University, Ames, IA 50011, USA \\ 4 Department of Food Science and Human Nutrition, Iowa State University, Ames, IA 50011, USA; \\ murli@iastate.edu \\ * Correspondence: koziel@iastate.edu; Tel.: +1-515-294-4206
}

Received: 1 June 2017; Accepted: 30 June 2017; Published: 5 July 2017

\begin{abstract}
The aroma profile of red wine is complex and research focusing on aroma compounds and their links to viticultural and enological practices is needed. Current research is limited to wines made from cold-hardy cultivars (interspecific hybrids of vinifera and native N. American grapes). The objective of this research was to develop a fully automated solid phase microextraction (SPME) method, using tandem gas chromatography-mass spectrometry (GC-MS)-olfactometry for the simultaneous chemical and sensory analysis of volatile/semi-volatile compounds and aroma in cold-hardy red wines. Specifically, the effects of SPME coating selection, extraction time, extraction temperature, incubation time, sample volume, desorption time, and salt addition were studied. The developed method was used to determine the aroma profiles of seven selected red wines originating from four different cold-hardy grape cultivars. Thirty-six aroma compounds were identified from Maréchal Foch, St. Croix, Frontenac, Vincent, and a Maréchal Foch/Frontenac blend. Among these 36 aroma compounds, isoamyl alcohol, ethyl caproate, benzeneethanol, ethyl decanoate, and ethyl caproate are the top five most abundant aroma compounds. Olfactometry helps to identify compounds not identified by MS. The presented method can be useful for grape growers and wine makers for the screening of aroma compounds in a wide variety of wines and can be used to balance desired wine aroma characteristics.
\end{abstract}

Keywords: cold-hardy grapes; wine; gas chromatography-mass spectrometry (GC-MS); olfactometry; solid phase microextraction (SPME); aroma

\section{Introduction}

In order to understand the aroma of wine and make a marketable product, it is necessary to separate, identify, and quantify the chemical compounds that impart these aromas. Aromas to note are the primary (varietal aroma), secondary (aromas due to fermentation from yeasts), and bouquet (aromas due to aging and storage) aromas. The pleasant volatiles in wines are due to the presence of higher aliphatic alcohols, ethyl esters, and acetates [1,2]. Wine aroma increased in complexity after malo-lactic fermentation (MLF), which produces changes in the carbonyl compounds [3]. Wines that have undergone MLF can be associated with herbaceous aromas from aliphatic aldehydes $[4,5]$ or buttery aromas from diacetyl [6]. Wine can also have off odors due to volatile sulfur compounds, described as garlic, onion, or cabbage [7]. Vinylphenols have been described as phenolic, medicinal, 
smoky, spicy, and clove-like [8,9]. An experienced palate can often distinguish the "foxy" characteristic of the main North American vines (Vitis labrusca and Vitis rotundifolia) from vinifera vines caused by methyl anthranilate [9,10].

Cold climate grapes are newer, and the aroma profiles are less characterized than Vinifera varieties. The identification and quantification of the most aromatic compounds can help the industry maximize the aroma quality in these wines. The varietal flavor profile was used to demonstrate good examples of wine production and the best grape growing and innovative vinification techniques. The first step in the aroma analysis of wines is to extract volatile organic compounds (VOCs). Solid phase microextraction (SPME) coupled with gas chromatography-mass spectrometry (GC-MS) is useful in extracting and pre-concentrating VOCs in wine. The inception of GC-olfactometry (GC-O) in 1964 allowed researchers to link an aroma descriptor to these separated compounds [11]. Although many detectors have been used to identify and quantify aroma compounds from wine, MS is the most widely used [12]. A review and summary of many experimental parameters are available elsewhere [12,13].

In this research, an automated headspace SPME-GCMS-O method was developed and the aroma profiles of seven cold-hardy wine samples were investigated. The chemicals in selected cold-hardy wines were isolated and tentatively identified by matching the mass spectral and aroma character. The grape and wine industry has expanded exponentially in cold climates. Therefore, there is a need to research aroma compounds and their links to grape growing and wine making practices in cold climates. Such information can be used for the monitoring of fruit maturity, developing the best viticultural and wine making practices, and the development of appropriate wine styles specific to cold climates. The flavor and aroma profiling of cold-hardy wine enables the development of high quality and unique wines. Therefore, a method was developed to evaluate the full chemical and sensory aroma profile of wine from cold climate grapes.

\section{Materials and Methods}

\subsection{Samples, Internal Standard, SPME}

Seven different red wines were obtained from various wineries in Iowa. Varieties included two Maréchal Foch from separate wineries, two Frontenac from separate wineries, a St. Croix, a Vincent, and a Maréchal Foch/Frontenac blend. Wines were not stored after initial opening for analysis. 3-nonanone (99\%), CAS 925-78-0 (Sigma-Aldrich, St. Louis, MO, USA), was used as an internal standard (IS) for the semi-quantification of aroma compounds. 3-nonanone was chosen because the compound is odor-active and not present in these wine samples. The final concentration of IS in wine $(0.206 \mathrm{mg} / \mathrm{L})$ was achieved by adding $10 \mu \mathrm{L}$ of IS in ethanol $(82.5 \mathrm{mg} / \mathrm{L})$ to each $4 \mathrm{~mL}$ of wine. Each wine sample bottle was opened immediately before each analysis, and triplicate runs were performed for each experiment $(n=3)$. SPME fibers with seven different coatings were purchased from Sigma-Aldrich (St. Louis, MO, USA). These coatings included: $50 / 30 \mu \mathrm{m}$ Divinylbenzene (DVB)/Carboxen (CAR)/Polydimethylsiloxane (PDMS), $100 \mu \mathrm{m}$ PDMS, $7 \mu \mathrm{m}$ PDMS, $85 \mu \mathrm{m}$ Polyacrylate (PA), $65 \mu \mathrm{m}$ PDMS/DVB, $70 \mu \mathrm{m}$ Carbowax (CW)/DVB, and $85 \mu \mathrm{m}$ CAR/PDMS. All SPME fibers were $1 \mathrm{~cm}$ in length. Details of SPME fiber cores, coatings, and the internal structure can be found elsewhere [14].

The optimized method used for the automated analysis of wine aroma used a $1 \mathrm{~cm} \mathrm{50/30 \mu \textrm {m }}$ DVB/CAR/PDMS SPME fiber, 10 min extraction time at $50^{\circ} \mathrm{C}$, and 2 min desorption in the heated GC inlet. A $10 \mathrm{~min}$ incubation in the heated agitator was used to equilibrate VOCs in the headspace of $4 \mathrm{~mL}$ of the wine sample in a $10 \mathrm{~mL}$ vial, facilitated by the addition of $2 \mathrm{~g}$ of sodium chloride.

\subsection{GC-MS-Olfactometry System}

The analysis was performed on a standard 6890N GC/5973Network Platform (Agilent Technologies, Santa Clara, CA, USA) and a CTC CombiPal ${ }^{\mathrm{TM}}$ autosampler equipped with a heated agitator (Trajan Scientific, Pflugerville, TX, USA). A constant agitation speed of $500 \mathrm{rpm}$ was used 
throughout this research, so that extraction would only depend on the SPME fiber geometry and diffusion coefficients of the aroma compounds. The instrument was modified after marketing with a Dean's switch for heartcutting, the ability for cryogenic focusing, FID, and the olfactometry port. A detailed schematic of the instrument can be found elsewhere [15]. The GC contains two columns connected in series. The first non-polar column was BPX-5 stationary phase with the following dimensions: $43.5 \mathrm{~m}$ length $\times 0.53 \mathrm{~mm}$ ID $\times 1.0 \mu \mathrm{m}$ film thickness (SGE Analytical Science, by Trajan, Austin, TX, USA). The second cross-linked polar column was BP-20 (Wax) with the following dimensions: $25 \mathrm{~m}$ length $\times 0.53 \mathrm{~mm}$ ID $\times 1.0 \mu \mathrm{m}$ film thickness (SGE Analytical Science, by Trajan, Austin, TX, USA). A constant pressure of 5.8 psi was provided at the midpoint between the first and second column using MultiTrax ${ }^{\mathrm{TM}}$ V.6.00 (Microanalytics, a Volatile Analysis company, Round Rock, TX, USA) system automation and MSD ChemStation ${ }^{\mathrm{TM}}$ E.01.01.335 data acquisition software (Agilent Technologies, Santa Clara, CA, USA). Additional analysis to obtain the total compound chromatogram (TCC) was done using a MassHunter Workstation (Agilent, Santa Clara, CA, USA). Flow from the second analytical column was directed to the single quadrupole mass selective detector and the olfactometry port by fixed restrictor tubing in an open-split interface.

For this research, a full heartcut was utilized from 0.05 to $35.00 \mathrm{~min}$. In other words, the sample flow was first directed through the non-polar column, and then the second polar column, yielding results similar to a mid-polarity GC separation on a long column. Therefore, retention indices were not used for identification in this research, due to the configuration of the two GC capillary columns connected in series.

The following instrument parameters were used: GC inlet temperature, $260{ }^{\circ} \mathrm{C}$; FID, $280^{\circ} \mathrm{C}$; column, $40{ }^{\circ} \mathrm{C}$ initial, $3.0 \mathrm{~min}$ hold, $7{ }^{\circ} \mathrm{C}$ per min ramp, $220^{\circ} \mathrm{C}$ final, 11.29 min hold; carrier gas, UHP helium (99.999\%) with an inline filter trap. The mass detector was operated in electron ionization (EI) mode with an ionization energy of $70 \mathrm{eV}$. The mass detector ion source and quadrupole were held at $230{ }^{\circ} \mathrm{C}$ and $150{ }^{\circ} \mathrm{C}$, respectively. Full spectrum scans were collected with the mass filter set from $\mathrm{m} / \mathrm{z}$ 33 to $m / z$ 450. The MS was auto-tuned daily before analysis. The use of a full scan for data acquisition allowed for library search techniques using NIST05 and Wiley 6th edition mass spectral databases.

Olfactometry data was generated using AromaTrax ${ }^{\mathrm{TM}}$ V.6.61 software (Microanalytics, a Volatile Analysis company, Grant, AL, USA). Recorded parameters included an aroma descriptor and the perceived intensity. The editable descriptor panel is shown in Figure 1. The area under the peak of each aroma note in the aromagram is calculated as width $\times$ intensity $\times 100$, where the width is the length of time that the aroma persisted in minutes. The sum of the areas under the peaks in the aromagram is the total odor, a dimensionless value used to analyze the total aroma detected by the human nose.

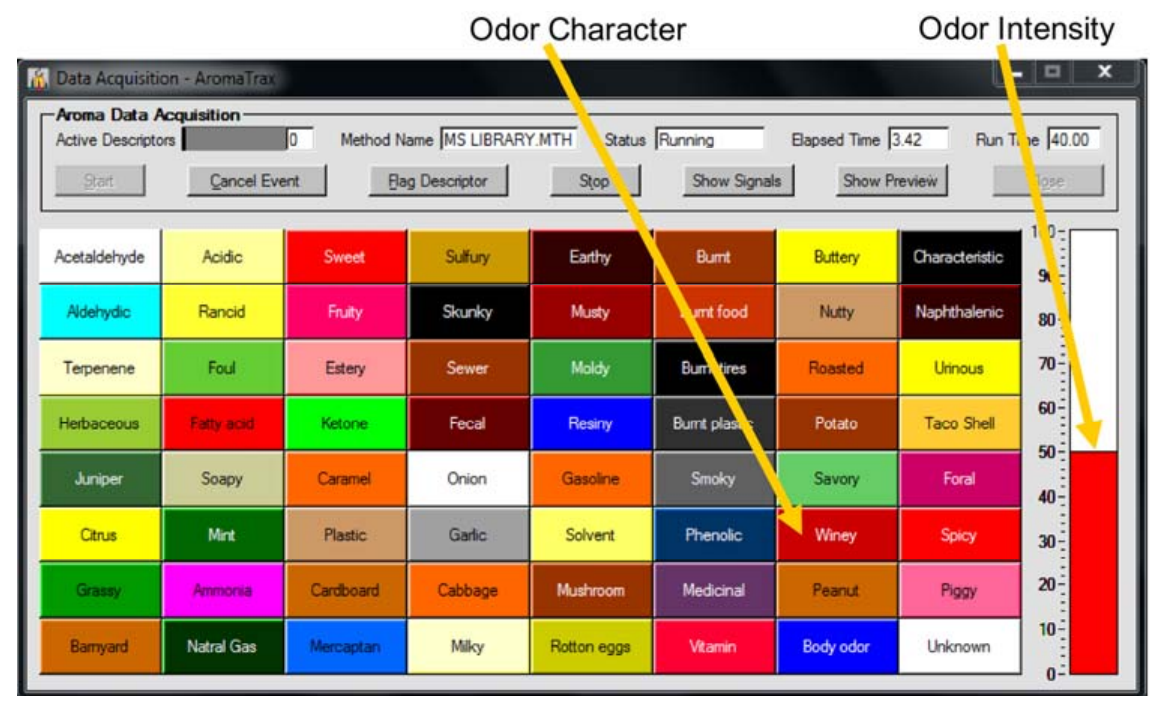

Figure 1. Aroma descriptor panel used to characterize volatiles and perceived intensities. 


\section{Results}

\subsection{SPME Optimization}

\subsubsection{SPME Coating Selection}

Seven commercially available SPME coatings were selected for optimization in the extraction of aroma compounds from Iowa red wines (Table 1). The response of the mass spectrometer to volatiles detected throughout the run was used to determine the extraction efficiency of the SPME coating. It was shown that the use of a 50/30 $\mu \mathrm{m}$ DVB/CAR/PDMS SPME coating was most appropriate for the rest of the experiments. In Table 1, a coating with a number lower than 100 indicates a lower extraction efficiency for that analyte when compared to 50/30 $\mu \mathrm{m}$ DVB/CAR/PDMS. These analytes spanned the entire chromatographic run, representing the range of analytes in wine aroma.

Table 1. Optimization of solid phase microextraction (SPME) extraction conditions-Fiber selection.

\begin{tabular}{|c|c|c|c|c|c|c|c|c|}
\hline RT (min) & Compound & $\begin{array}{l}50 / 30 \mu \mathrm{m} \\
\text { DVB/CAR/ } \\
\text { PDMS }\end{array}$ & $\begin{array}{l}100 \mu \mathrm{m} \\
\text { PDMS }\end{array}$ & $\begin{array}{l}7 \mu \mathrm{m} \\
\text { PDMS }\end{array}$ & $\begin{array}{c}85 \mu \mathrm{m} \\
\text { PA }\end{array}$ & $\begin{array}{c}65 \mu \mathrm{m} \\
\text { PDMS/DVB }\end{array}$ & $\begin{array}{c}70 \mu \mathrm{m} \\
\text { CW/DVB }\end{array}$ & $\begin{array}{c}85 \mu \mathrm{m} \\
\text { CAR/PDMS }\end{array}$ \\
\hline 4.77 & Ethyl isobutyrate & 100 & 58 & 0 & 13 & 75 & 29 & 104 \\
\hline 5.53 & Isobutyl alcohol & 100 & 42 & 1 & 95 & 81 & 97 & 83 \\
\hline 8.10 & Isoamyl alcohol & 100 & 35 & 0 & 73 & 75 & 66 & 92 \\
\hline 11.00 & Ethyl lactate & 100 & 17 & 0 & 71 & 60 & 79 & 132 \\
\hline 11.75 & Ethyl caproate & 100 & 24 & 0 & 7 & 53 & 17 & 109 \\
\hline 12.92 & Acetic acid & 100 & 5 & 3 & 124 & 38 & 242 & 158 \\
\hline 16.38 & Ethyl caprylate & 100 & 67 & 1 & 21 & 98 & 45 & 64 \\
\hline 18.44 & Vitispirane & 100 & 61 & 0 & 16 & 90 & 38 & 99 \\
\hline 18.34 & Diethyl succinate & 100 & 52 & 0 & 45 & 105 & 56 & 63 \\
\hline 20.42 & Ethyl decanoate & 100 & 114 & 12 & 56 & 121 & 72 & 53 \\
\hline 21.13 & Benzenethanol & 100 & 23 & 0 & 74 & 86 & 67 & 82 \\
\hline 24.03 & Ethyl myristate & 100 & 94 & 32 & 59 & 92 & 66 & 41 \\
\hline 30.37 & Ethyl palmitate & 100 & 187 & 132 & 135 & 194 & 155 & 17 \\
\hline
\end{tabular}

Bolded numbers indicate when a SPME fiber coating extracted more mass than the 50/30 $\mu \mathrm{m}$ DVB/CAR/PDMS coating. DVB: Divinylbenzene; PA: Polyacrylate; PDMS: Polydimethylsiloxane; CW: Carbowax; CAR: Carboxen.

\subsubsection{Extraction Time}

Different extraction times were tested using the autosampler. These times were $10 \mathrm{~s}, 30 \mathrm{~s}, 1 \mathrm{~min}$, $3 \mathrm{~min}, 5 \mathrm{~min}, 10 \mathrm{~min}, 15 \mathrm{~min}, 20 \mathrm{~min}, 30 \mathrm{~min}$, and $60 \mathrm{~min}$. Plots of the mass extracted versus the extraction time varied in shape. The profiles were typically linear or logarithmic, with the exception of acetic acid (Figure 2). Equilibrium was reached for most compounds (i.e., the logarithmic curve had started to flatten out), and was not excessively long, with a figure of about $10 \mathrm{~min}$. Additional SPME fiber sorption capacity limitations were noticed after $10 \mathrm{~min}$, for example, ethyl isobutyrate, ethyl lactate, and acetic acid. An extraction time of $10 \mathrm{~min}$ was chosen to avoid these possible interactions due to competitive adsorption and apparent analyte displacement after $10 \mathrm{~min}$. 

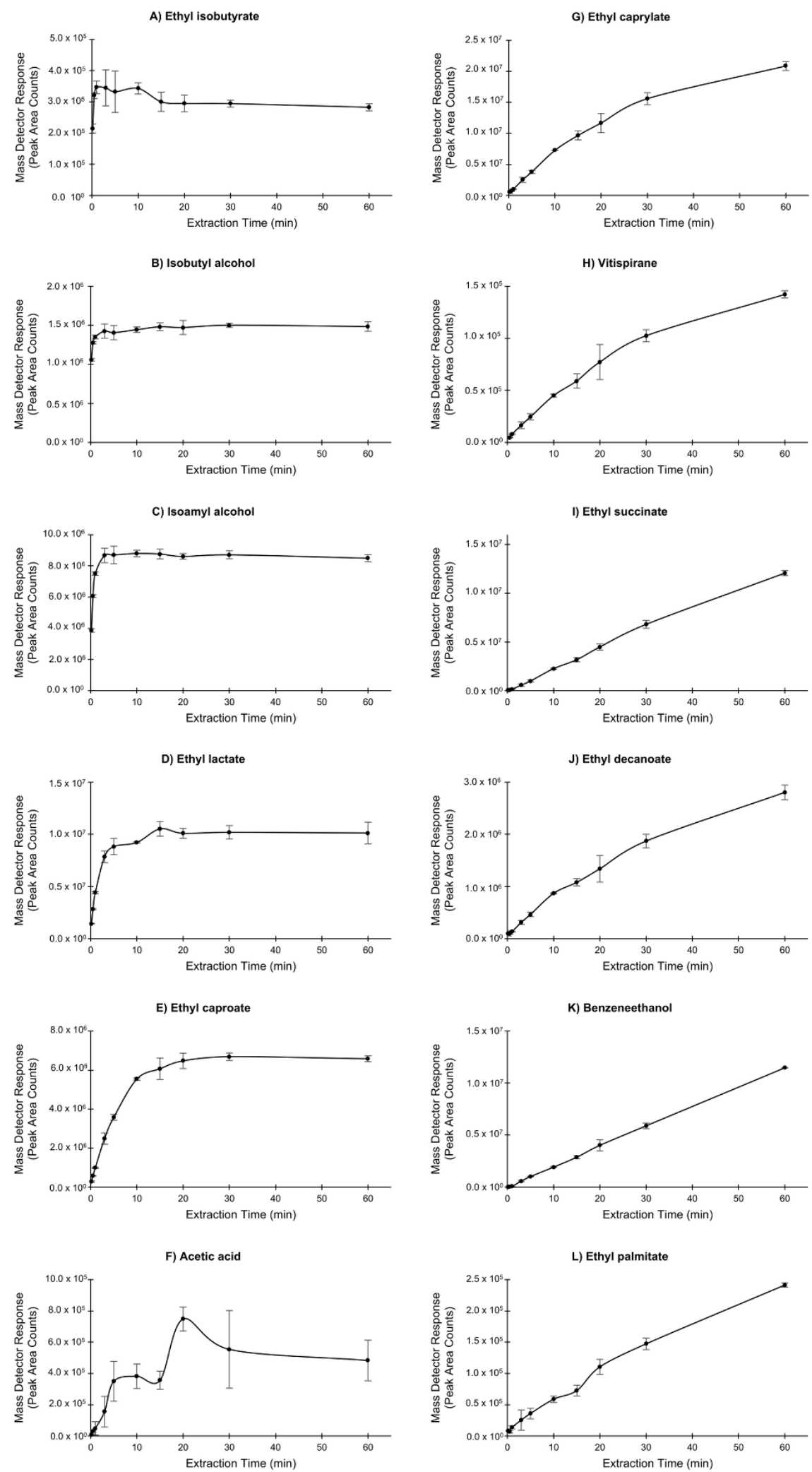

Figure 2. Extraction time profile of selected volatiles extracted with HS-SPME in an Iowa Maréchal Foch. Conditions: 5 min pre-sampling desorption of 50/30 $\mu \mathrm{m}$ DVB/CAR/PDMS SPME fiber; $4 \mathrm{~mL}$ wine sample in a $10 \mathrm{~mL}$ threaded glass amber vial with PTFE/silicone septa; $10 \mathrm{~min}$ incubation at $35^{\circ} \mathrm{C}$; $10 \mathrm{~s}, 30 \mathrm{~s}, 1 \mathrm{~min}, 3 \mathrm{~min}, 5 \mathrm{~min}, 10 \mathrm{~min}, 20 \mathrm{~min}, 30 \mathrm{~min}$, and $60 \mathrm{~min}$ extraction time at $35^{\circ} \mathrm{C}$; agitation speed $500 \mathrm{rpm} ; 5 \mathrm{~min}$ desorption time into GC inlet. $10 \mathrm{~min}$ extraction time was chosen for the method. 


\subsubsection{Extraction Temperature}

Extraction times can be shortened by the efficient use of a higher extraction temperature, as seen in Figure 3. Masses extracted of ethyl caprylate, ethyl succinate, ethyl decanoate, benzeneethanol, and ethyl palmitate increased with a higher temperature. Higher temperatures can also decrease the amount of analyte extracted, as observed in ethyl isobutyrate, isoamyl alcohol, and ethyl caproate. Extraction temperatures of $35,40,50,60,70$, and $80^{\circ} \mathrm{C}$ were investigated. To efficiently extract the range of volatiles and semi-volatiles, the optimal temperature chosen for this experiment was $50^{\circ} \mathrm{C}$.

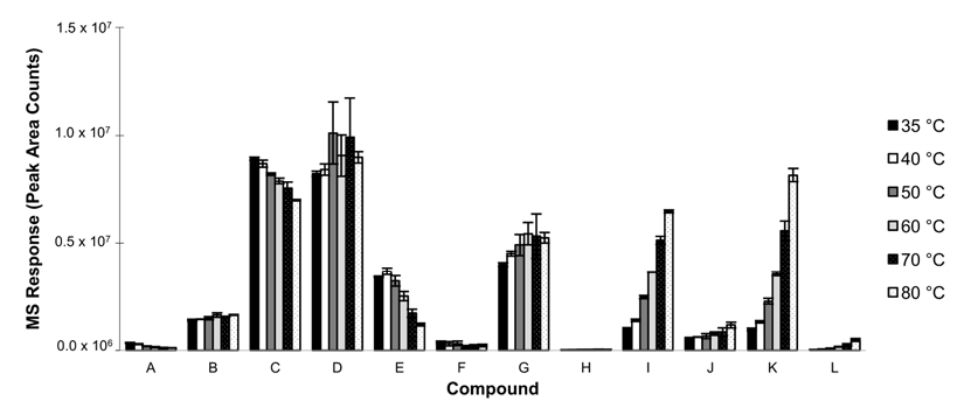

Figure 3. Effects of extraction temperature on selected volatiles extracted with HS-SPME in an Iowa Maréchal Foch. Compound letters correspond to compounds found in Figure 2 (i.e., A-ethyl isobutyrate, B-isobutyl alcohol, L-ethyl palmitate). Conditions: $5 \mathrm{~min}$ pre-sampling desorption of $50 / 30 \mu \mathrm{m}$ DVB/CAR/PDMS SPME fiber; $4 \mathrm{~mL}$ wine sample in a $10 \mathrm{~mL}$ threaded glass amber vial with PTFE/silicone septa; $10 \mathrm{~min}$ incubation at $35,40,50,60,70,80^{\circ} \mathrm{C} ; 10 \mathrm{~min}$ extraction time at 35,40 , $50,60,70,80^{\circ} \mathrm{C}$; agitation speed $500 \mathrm{rpm} ; 5 \mathrm{~min}$ desorption time into GC inlet. $50^{\circ} \mathrm{C}$ was chosen for the method.

\subsubsection{Incubation Time}

An extended incubation time allows for volatiles to equilibrate in the headspace before sampling. This was useful in the extraction of less volatile compounds in the wine sample, such as ethyl caprylate or ethyl decanoate (Figure 4). The incubation time did not have a large effect on the extraction efficiency of more volatile compounds such as ethyl isobutyrate, isobutyl alcohol, and isoamyl alcohol, likely due to their abundance in the headspace of the sample. Incubation times of 0,5 $\mathrm{min}, 10 \mathrm{~min}, 15 \mathrm{~min}$, and $20 \mathrm{~min}$ were investigated to establish the equilibrium of analytes in the headspace. The incubation time of 10 min was chosen, as determined by the extracted mass of semi-volatiles.

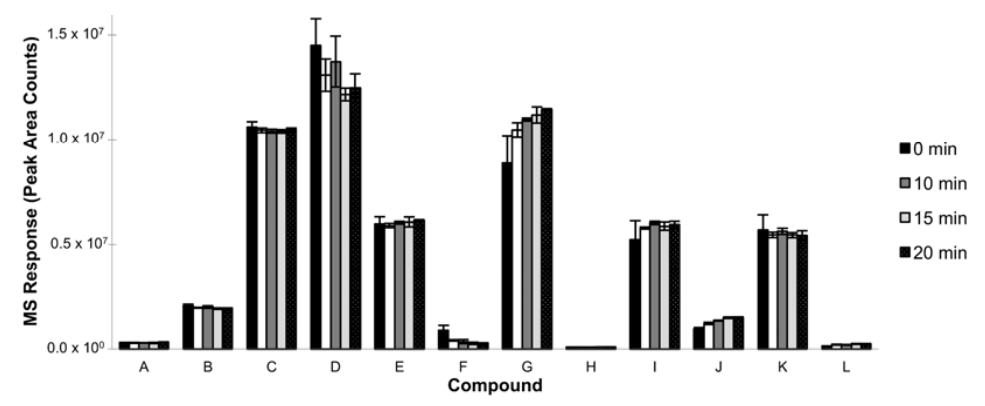

Figure 4. Effects of incubation time on selected volatiles extracted using HS-SPME in an Iowa Maréchal Foch. Compound letters correspond to compounds found in Figure 2 (i.e., A-ethyl isobutyrate, B-isobutyl alcohol, L—ethyl palmitate). Conditions: 5 min pre-sampling desorption of 50/30 $\mu \mathrm{m}$ DVB/CAR/PDMS SPME fiber; $4 \mathrm{~mL}$ wine sample in a $10 \mathrm{~mL}$ threaded glass amber vial with $\mathrm{PTFE} /$ silicone septa; 0, $5 \mathrm{~min}, 10 \mathrm{~min}, 15 \mathrm{~min}$, and $20 \mathrm{~min}$ incubation at $50{ }^{\circ} \mathrm{C} ; 10 \mathrm{~min}$ extraction time at $50{ }^{\circ} \mathrm{C}$; agitation speed $500 \mathrm{rpm} ; 5 \mathrm{~min}$ desorption time into GC inlet. $10 \mathrm{~min}$ incubation time was chosen for the method. 


\subsubsection{Sample Volume}

A $10 \mathrm{~mL}$ glass amber vial was used with the autosampler. The sample volume was investigated to maximize the mass extracted from the headspace by SPME. A higher volume of wine would yield a greater mass of volatiles in the headspace, up to the equilibrium. This was observed as an increase in the mass extracted was directly proportional to an increase in the sample volume in ethyl caproate, ethyl caprylate, ethyl succinate, ethyl decanoate, benzeneethanol, and ethyl palmitate (Figure 5). From this experiment, a $4 \mathrm{~mL}$ sample volume in a $10 \mathrm{~mL}$ vial was chosen for the method.

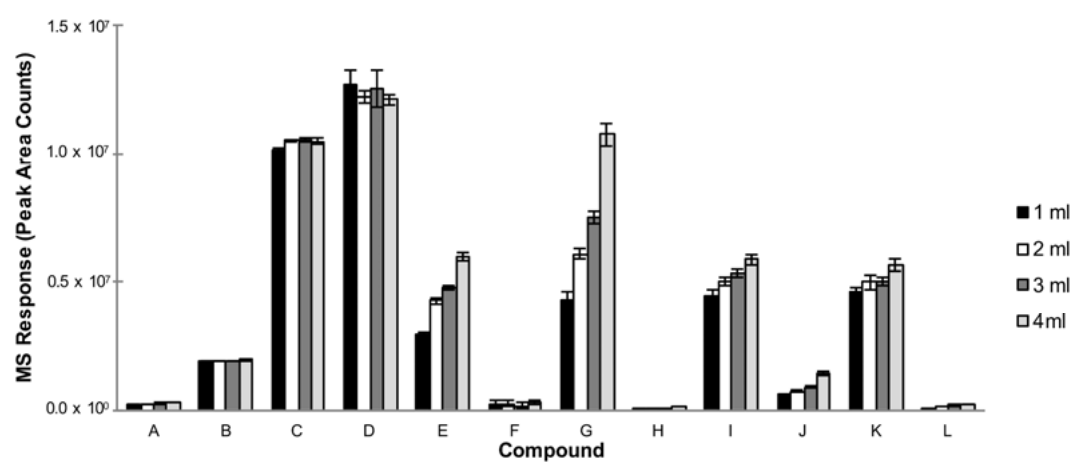

Figure 5. Effects of sample volume on selected volatiles extracted using HS-SPME in an Iowa Maréchal Foch. Compound letters correspond to compounds found in Figure 2 (i.e., A-ethyl isobutyrate, B-isobutyl alcohol, L-ethyl palmitate). Conditions: 5 min pre-sampling desorption of 50/30 $\mu \mathrm{m}$ DVB/CAR/PDMS SPME fiber; 1, 2, 3, and $4 \mathrm{~mL}$ wine sample in a $10 \mathrm{~mL}$ threaded glass amber vial with PTFE/silicone septa; $10 \mathrm{~min}$ incubation at $50{ }^{\circ} \mathrm{C} ; 10 \mathrm{~min}$ extraction time at $50{ }^{\circ} \mathrm{C}$; agitation speed $500 \mathrm{rpm} ; 5 \mathrm{~min}$ desorption time into GC inlet. $4 \mathrm{~mL}$ sample volume was chosen for the method.

\subsubsection{Desorption Time}

Optimizing the desorption time maximizes the transfer of analytes into the instrument for analysis. Desorption times of $30 \mathrm{~s}, 60 \mathrm{~s}, 120 \mathrm{~s}, 180 \mathrm{~s}, 240 \mathrm{~s}$, and $300 \mathrm{~s}$ were used to determine the minimum time needed to desorb analytes from the SPME fiber (Figure 6). A desorption time of $120 \mathrm{~s}$ was chosen in a $260{ }^{\circ} \mathrm{C}$ injector. The inlet pressure was constant and determined by the pressure needed to maintain balance with the midpoint pressure.

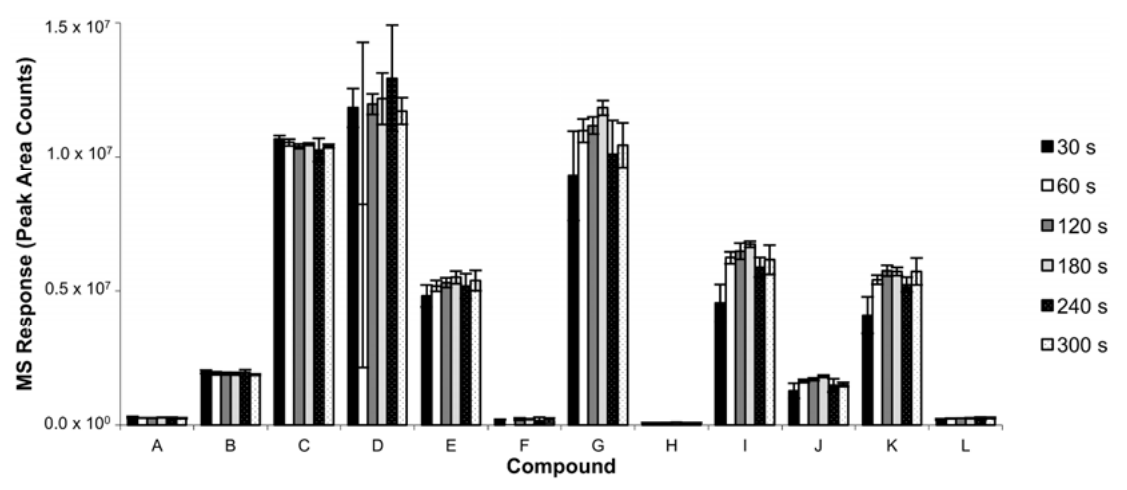

Figure 6. Effects of fiber desorption time on selected volatiles extracted in an Iowa Maréchal Foch. Compound letters correspond to compounds found in Figure 2 (i.e., A-ethyl isobutyrate, B-isobutyl alcohol, L-ethyl palmitate). Conditions: 30 s, 60 s, 120 s, 180 s, 240 s, 300 s pre-sampling desorption of $50 / 30 \mu \mathrm{m}$ DVB/CAR/PDMS SPME fiber; $4 \mathrm{~mL}$ wine sample in a $10 \mathrm{~mL}$ threaded glass amber vial with $\mathrm{PTFE} /$ silicone septa; $10 \mathrm{~min}$ incubation at $50{ }^{\circ} \mathrm{C} ; 10 \mathrm{~min}$ extraction time at $50{ }^{\circ} \mathrm{C}$; agitation speed 500 rpm; 30 s, 60 s, 120 s, 180 s, 240 s, 300 s desorption time into GC inlet. 120 s thermal desorption time was chosen for the method. 


\subsubsection{Salt Addition}

The addition of sodium chloride was used to adjust the ionic strength of the wine sample. This salting-out effect can help drive analytes to the SPME coating with increasing amounts of salt. The addition of $0.5,1.0,1.5,2$, and $2.5 \mathrm{~g}$ of salt was investigated to maximize the extraction efficiency (Figure 7). For this experiment, a $2.0 \mathrm{~g}$ addition of sodium chloride was chosen for the method.

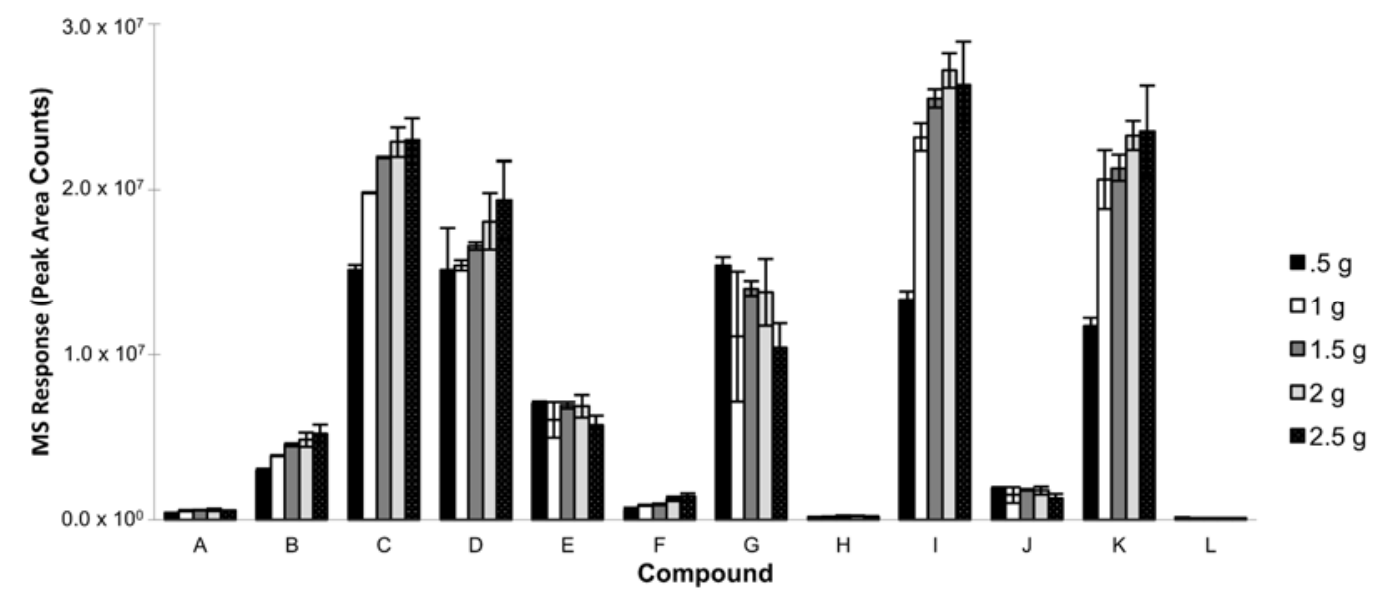

Figure 7. Effects of salt addition on selected volatiles extracted in an Iowa Maréchal Foch. Compound letters correspond to compounds found in Figure 2 (i.e., A-ethyl isobutyrate, B-isobutyl alcohol, L-ethyl palmitate). Conditions: 30, 60, 120, 180, 240, 300 s pre-sampling desorption of 50/30 $\mu \mathrm{m}$ DVB/CAR/PDMS SPME fiber; $4 \mathrm{~mL}$ wine sample in a $10 \mathrm{~mL}$ threaded glass amber vial with PTFE/silicone septa; $10 \mathrm{~min}$ incubation at $50{ }^{\circ} \mathrm{C} ; 10 \mathrm{~min}$ extraction time at $50{ }^{\circ} \mathrm{C}$; agitation speed $500 \mathrm{rpm} ; 30,60$, 120, 180, 240, $300 \mathrm{~s}$ desorption time into GC inlet. $120 \mathrm{~s}$ thermal desorption time was chosen for the method.

\subsection{Analysis of Wine Samples}

\section{GC-MS-Olfactometry}

Tentative identifications of thirty-six compounds by the mass spectral match of their most significant red wine aroma compounds with the ratio of their compound peak area to the internal standard peak area are listed in Table 2. The molecular weight of the compounds identified by mass spectral match ranged from 60 to $284 \mathrm{amu}$. The relative quantity of each compound to the corresponding ones in the other wine samples was calculated by the peak area to internal standard ratio. The aroma profile of the seven Iowa red wines varied considerably between samples. These results can reflect the influence of the climate, grape variety, vintage, and different viticultural and enological practices in seven different Iowa red wines. Further research is warranted to link the variables to wine aroma. 
Table 2. Tentative identification by mass spectral match of the most significant red wine aroma wine aroma compounds, listed as the volatile compound peak area: internal standard peak area ratio.

\begin{tabular}{|c|c|c|c|c|c|c|c|c|c|c|c|c|}
\hline$\#$ & RT (min) & LRI $^{A}$ & Stationary Phase ${ }^{1-10}$ & Compound & MW & ${ }^{\text {B }}$ Foch & ${ }^{B}$ St. Croix & ${ }^{B}$ Frontenac & ${ }^{B}$ Foch/Frontenac & ${ }^{C}$ Vincent & ${ }^{D}$ Frontenac & $\mathrm{D}_{\text {Foch }}$ \\
\hline 1 & 3.58 & $\begin{array}{l}949 \\
963 \\
955 \\
558 \\
619 \\
575 \\
976\end{array}$ & $\begin{array}{l}2 \\
2 \\
4 \\
5 \\
8 \\
8 \\
9\end{array}$ & 2,3-Butanedione & 86 & 1.11 & 5.18 & 0.85 & 0.32 & 0.94 & 1.39 & 1.05 \\
\hline 2 & 3.7 & $\begin{array}{l}880 \\
710\end{array}$ & $\begin{array}{l}2 \\
8\end{array}$ & Acetal & 118 & 1.24 & 0.96 & 8.57 & 23.1 & 6.75 & 4.9 & 8.08 \\
\hline 3 & 4.08 & 774 & 3 & Ethyl propanoate & 102 & 1.73 & 1.05 & 7.26 & 19.6 & 3.42 & 6.85 & 5.38 \\
\hline 4 & 4.72 & $\begin{array}{l}956 \\
746\end{array}$ & $\begin{array}{l}2 \\
8\end{array}$ & Ethyl isobutyrate & 116 & 5.94 & 1.67 & 3.99 & 3.54 & 6.36 & 2.3 & 1 \\
\hline 5 & 5.49 & $\begin{array}{c}1110 \\
1054 \\
1083 \\
1093 \\
609 \\
616\end{array}$ & $\begin{array}{l}2 \\
2 \\
4 \\
4 \\
6 \\
8 \\
\end{array}$ & Isobutyl alcohol & 74 & 14.6 & 23.8 & 21.9 & 27.6 & 86.1 & 21.4 & 28.7 \\
\hline 6 & 6.07 & $\begin{array}{l}863 \\
788\end{array}$ & $\begin{array}{l}3 \\
5\end{array}$ & Ethyl butanoate & 116 & 1.55 & 3.43 & 3.5 & 2.2 & 2.63 & 1.05 & 3.59 \\
\hline 7 & 6.66 & $\begin{array}{c}1138 \\
1149 \\
634 \\
653\end{array}$ & $\begin{array}{l}4 \\
4 \\
5 \\
6 \\
\end{array}$ & n-Butanol & 74 & 0.9 & 1.85 & 1.44 & 4.07 & 1.76 & 4.32 & 1.68 \\
\hline 8 & 7.22 & $\begin{array}{c}1060 \\
856 \\
840\end{array}$ & $\begin{array}{l}2 \\
6 \\
8\end{array}$ & Ethyl isovalerate & 130 & 4.29 & 0.41 & 2 & 1.76 & 0.9 & 0.38 & 0.29 \\
\hline 9 & 8.05 & $\begin{array}{c}1184 \\
719\end{array}$ & $\begin{array}{l}2 \\
8\end{array}$ & Isoamyl alcohol & 88 & 132 & 355 & 275 & 477 & 475 & 221 & 377 \\
\hline 10 & 8.12 & $\begin{array}{c}1110 \\
860\end{array}$ & $\begin{array}{l}2 \\
8\end{array}$ & Isoamyl acetate & 130 & 32.2 & 3.89 & 3.87 & 4.02 & 3.89 & 3.22 & 0 \\
\hline 11 & 10.03 & 1250 & 2 & Styrene & 104 & nd & 16.9 & 3.22 & 0.05 & 0.03 & nd & 0.68 \\
\hline
\end{tabular}


Table 2. Cont

\begin{tabular}{|c|c|c|c|c|c|c|c|c|c|c|c|c|}
\hline$\#$ & RT (min) & LRI $^{A}$ & Stationary Phase ${ }^{1-10}$ & Compound & MW & ${ }^{B}$ Foch & ${ }^{B}$ St. Croix & ${ }^{B}$ Frontenac & ${ }^{B}$ Foch/Frontenac & ${ }^{C}$ Vincent & ${ }^{D}$ Frontenac & $\mathrm{D}_{\text {Foch }}$ \\
\hline \multirow[t]{3}{*}{12} & 10.91 & 1312 & 2 & Ethyl lactate & 118 & 13.7 & 34.1 & 39.9 & 34.3 & 30 & 67.1 & 19.8 \\
\hline & & 1341 & 4 & & & & & & & & & \\
\hline & & 803 & 8 & & & & & & & & & \\
\hline \multirow[t]{8}{*}{13} & 11.15 & 1230 & 2 & Ethyl caproate & 144 & 26.4 & 71 & 40.4 & 33 & 34.7 & 21.5 & 64.3 \\
\hline & & 1060 & 3 & & & & & & & & & \\
\hline & & 1232 & 4 & & & & & & & & & \\
\hline & & 1238 & 4 & & & & & & & & & \\
\hline & & 985 & 5 & & & & & & & & & \\
\hline & & 981 & 5 & & & & & & & & & \\
\hline & & 996 & 6 & & & & & & & & & \\
\hline & & 996 & 6 & & & & & & & & & \\
\hline \multirow[t]{9}{*}{14} & 11.27 & 1316 & 2 & n-Hexanol & 102 & 8.64 & 0 & 0 & 19.6 & 12.6 & 7.82 & 51.7 \\
\hline & & 1330 & 2 & & & & & & & & & \\
\hline & & 1332 & 2 & & & & & & & & & \\
\hline & & 1352 & 4 & & & & & & & & & \\
\hline & & 847 & 5 & & & & & & & & & \\
\hline & & 848 & 5 & & & & & & & & & \\
\hline & & 848 & 5 & & & & & & & & & \\
\hline & & 862 & 6 & & & & & & & & & \\
\hline & & 1354 & 9 & & & & & & & & & \\
\hline \multirow[t]{8}{*}{15} & 12.81 & 1400 & 2 & Acetic acid & 60 & 51.4 & 6.61 & 58.2 & 10.6 & 11.6 & 13.2 & 18.7 \\
\hline & & 1401 & 2 & & & & & & & & & \\
\hline & & 791 & 3 & & & & & & & & & \\
\hline & & 1435 & 4 & & & & & & & & & \\
\hline & & 1442 & 4 & & & & & & & & & \\
\hline & & 1459 & 4 & & & & & & & & & \\
\hline & & 621 & 5 & & & & & & & & & \\
\hline & & 723 & 8 & & & & & & & & & \\
\hline \multirow[t]{5}{*}{16} & 13.25 & 1437 & 2 & Furfural & 96 & nd & nd & nd & 10.2 & nd & nd & nd \\
\hline & & 1438 & 2 & & & & & & & & & \\
\hline & & 1450 & 2 & & & & & & & & & \\
\hline & & 1449 & 2 & & & & & & & & & \\
\hline & & 1447 & 4 & & & & & & & & & \\
\hline
\end{tabular}


Table 2. Cont

\begin{tabular}{|c|c|c|c|c|c|c|c|c|c|c|c|c|}
\hline \multirow[t]{12}{*}{$\#$} & RT (min) & LRI $^{A}$ & Stationary Phase ${ }^{1-10}$ & Compound & MW & ${ }^{B}$ Foch & ${ }^{B}$ St. Croix & ${ }^{B}$ Frontenac & ${ }^{B}$ Foch/Frontenac & ${ }^{\mathrm{C}}$ Vincent & ${ }^{D}$ Frontenac & D Foch \\
\hline & & 1456 & 4 & & & & & & & & & \\
\hline & & 1466 & 4 & & & & & & & & & \\
\hline & & 1465 & 4 & & & & & & & & & \\
\hline & & 802 & 5 & & & & & & & & & \\
\hline & & 829 & 5 & & & & & & & & & \\
\hline & & 800 & 5 & & & & & & & & & \\
\hline & & 800 & 5 & & & & & & & & & \\
\hline & & 836 & 6 & & & & & & & & & \\
\hline & & 868 & 6 & & & & & & & & & \\
\hline & & 830 & 6 & & & & & & & & & \\
\hline & & 815 & 8 & & & & & & & & & \\
\hline 17 & 13.57 & & & 3-Nonanone (IS) & 142 & 100 & 100 & 100 & 100 & 100 & 100 & 100 \\
\hline \multirow[t]{3}{*}{18} & 14.37 & 1375 & 1 & Methyl octanoate & 158 & 0.39 & 1.01 & 0.32 & 0.23 & 0.35 & 0.18 & 0.33 \\
\hline & & 1392 & 4 & & & & & & & & & \\
\hline & & 1109 & 10 & & & & & & & & & \\
\hline \multirow[t]{2}{*}{19} & 14.48 & 1692 & 2 & 1,3-Butanediol & 90 & 1.89 & 4.03 & 11 & 3.38 & 1.48 & 8.15 & 4.43 \\
\hline & & 941 & 8 & & & & & & & & & \\
\hline \multirow[t]{15}{*}{20} & 14.81 & 1518 & 1 & Benzaldehyde & 106 & 0.18 & 0.93 & 0.95 & 1.14 & 0.73 & 0.12 & 55.2 \\
\hline & & 1516 & 1 & & & & & & & & & \\
\hline & & 1509 & 2 & & & & & & & & & \\
\hline & & 1454 & 2 & & & & & & & & & \\
\hline & & 1520 & 2 & & & & & & & & & \\
\hline & & 1482 & 2 & & & & & & & & & \\
\hline & & 1502 & 2 & & & & & & & & & \\
\hline & & 1086 & 3 & & & & & & & & & \\
\hline & & 1515 & 4 & & & & & & & & & \\
\hline & & 1496 & 4 & & & & & & & & & \\
\hline & & 1513 & 4 & & & & & & & & & \\
\hline & & 1538 & 4 & & & & & & & & & \\
\hline & & 1530 & 4 & & & & & & & & & \\
\hline & & 1522 & 4 & & & & & & & & & \\
\hline & & 1516 & 4 & & & & & & & & & \\
\hline
\end{tabular}


Table 2. Cont.

\begin{tabular}{|c|c|c|c|c|c|c|c|c|c|c|c|c|}
\hline$\#$ & RT (min) & LRI $^{A}$ & Stationary Phase ${ }^{1-10}$ & Compound & MW & ${ }^{B}$ Foch & ${ }^{B}$ St. Croix & ${ }^{B}$ Frontenac & ${ }^{B}$ Foch/Frontenac & ${ }^{\mathrm{C}}$ Vincent & ${ }^{D}$ Frontenac & ${ }^{D}$ Foch \\
\hline & & 926 & 5 & & & & & & & & & \\
\hline & & 926 & 5 & & & & & & & & & \\
\hline & & 926 & 5 & & & & & & & & & \\
\hline & & 924 & 6 & & & & & & & & & \\
\hline & & 960 & 6 & & & & & & & & & \\
\hline & & 962 & 6 & & & & & & & & & \\
\hline & & 957 & 6 & & & & & & & & & \\
\hline & & 961 & 6 & & & & & & & & & \\
\hline & & 944 & 7 & & & & & & & & & \\
\hline & & 938 & 7 & & & & & & & & & \\
\hline & & 947 & 8 & & & & & & & & & \\
\hline & & 947 & 8 & & & & & & & & & \\
\hline & & 1540 & 9 & & & & & & & & & \\
\hline \multirow[t]{2}{*}{21} & 15.02 & 1501 & 2 & Isobutyric acid & 88 & 2.45 & 0.28 & 1.38 & 0.78 & 2.46 & 0.45 & 0.32 \\
\hline & & 935 & 3 & & & & & & & & & \\
\hline 22 & 15.15 & & & 2,3-Butanediol & 90 & 1.41 & 1.56 & 2.31 & 2.03 & 1.5 & 2.62 & 2.35 \\
\hline \multirow[t]{6}{*}{23} & 15.72 & 1258 & 3 & Ethyl caprylate & 172 & 164 & 398 & 209 & 116 & 187 & 181 & 205 \\
\hline & & 1429 & 4 & & & & & & & & & \\
\hline & & 1466 & 4 & & & & & & & & & \\
\hline & & 1196 & 6 & & & & & & & & & \\
\hline & & 1193 & 6 & & & & & & & & & \\
\hline & & 1195 & 6 & & & & & & & & & \\
\hline \multirow[t]{2}{*}{24} & 16.83 & 1631 & 2 & Isovaleric acid & 102 & 8.97 & 2.58 & 7.79 & 5.1 & 3.73 & 3.54 & 3.55 \\
\hline & & 834 & 6 & & & & & & & & & \\
\hline 25 & 17.66 & 1276 & 7 & Vitispirane & 192 & 0 & 3.02 & 0.31 & 4.5 & 15.7 & 3.39 & 0 \\
\hline 26 & 17.79 & 1278 & 5 & Ethyl nonanoate & 186 & 0.83 & nd & 1.68 & 0 & 0 & 0 & 0.78 \\
\hline \multirow[t]{2}{*}{27} & 17.99 & 1642 & 2 & Diethyl succinate & 174 & 3.62 & 11.5 & 18.9 & 43.8 & 12.9 & 5.77 & 122 \\
\hline & & 1153 & 8 & & & & & & & & & \\
\hline \multirow[t]{3}{*}{28} & 19.74 & 1390 & 6 & Ethyl decanoate & 200 & 54.9 & 99.5 & 83.9 & 29.8 & 33.3 & 98.5 & 34.4 \\
\hline & & 1391 & 6 & & & & & & & & & \\
\hline & & 1394 & 6 & & & & & & & & & \\
\hline
\end{tabular}

Note: \# is the chromatographic peak number. RT is the retention time in minutes. A is the GC capillary column linear retention index from the LRI \& Odour Database [16]. GC stationary phases are: 1-CP-Wax, 2-CW-20M, 3-DB-1701, 4-DB-Wax, 5-DB1, 6-DB5, 7-HP-1, 8-OV-101, 9-SP-Wax, 10-SPB-1. MW is the molecular weight. B, C, and D stand for the three different Iowa wineries. IS = internal standard. 
Table 2. Cont.

\begin{tabular}{|c|c|c|c|c|c|c|c|c|c|c|c|c|}
\hline$\#$ & RT (min) & LRI $^{A}$ & Stationary Phase ${ }^{1-10}$ & Compound & MW & ${ }^{B}$ Foch & B St. Croix & ${ }^{B}$ Frontenac & ${ }^{B}$ Foch/Frontenac & C Vincent & ${ }^{\mathrm{D}}$ Frontenac & $\mathrm{D}_{\text {Foch }}$ \\
\hline 29 & 20.27 & $\begin{array}{l}1788 \\
1785 \\
1233\end{array}$ & $\begin{array}{l}2 \\
2 \\
8\end{array}$ & Phenethyl acetate & 164 & 0.95 & 1.56 & 1.26 & 1.41 & 0.95 & 1.47 & 1.2 \\
\hline 30 & 20.98 & 1903 & 4 & Benzeneethanol & 122 & 41.3 & 146 & 56 & 232 & 111 & 53.7 & 134 \\
\hline 31 & 23.06 & $\begin{array}{l}2007 \\
2007 \\
2100 \\
2013 \\
2075 \\
1183 \\
1256\end{array}$ & $\begin{array}{l}2 \\
2 \\
2 \\
2 \\
4 \\
6 \\
7\end{array}$ & Octanoic acid & 144 & 1.39 & 1.07 & 6.63 & 0.09 & 1.99 & 2.22 & 0.7 \\
\hline 32 & 23.36 & 1595 & 6 & Ethyl laurate & 228 & 3.3 & 2.63 & 6.73 & 1.62 & 1.28 & 8.24 & 2.72 \\
\hline 33 & 24.76 & & & 4-Ethylphenol & 122 & nd & 7.49 & 2.32 & nd & nd & 3.4 & 2.33 \\
\hline 34 & 24.81 & & & 8-Pentadecanone & 226 & 1.06 & 7.49 & 2.31 & 2.53 & 2.33 & 3.4 & 2.32 \\
\hline 35 & 26.57 & & & Glycerol & 92 & nd & nd & 26.8 & nd & nd & nd & nd \\
\hline 36 & 26.63 & 1793 & 6 & Ethyl myristate & 256 & 0.39 & 0.53 & 0.48 & 0.38 & 0.57 & 0.84 & 0.99 \\
\hline 37 & 29.63 & $\begin{array}{l}1993 \\
1985\end{array}$ & $\begin{array}{l}6 \\
7\end{array}$ & Ethyl palmitate & 284 & 2.35 & 2.1 & 5.75 & 1.92 & 2.81 & 4.12 & 5.14 \\
\hline
\end{tabular}

Note: \# is the chromatographic peak number. RT is the retention time in minutes. A is the GC capillary column linear retention index from the LRI \& Odour Database [16]. GC stationary phases are: 1-CP-Wax, 2-CW-20M, 3-DB-1701, 4-DB-Wax, 5-DB1, 6-DB5, 7-HP-1, 8-OV-101, 9-SP-Wax, 10-SPB-1. MW is the molecular weight. B, C, and D stand for the three different Iowa wineries. IS = internal standard. 
Simultaneous olfactometry, when used with GC-MS, can verify compounds by aroma character. An example of this is highlighted in Figure 8. The chromatographic peak at 19 min was not identified by mass spectral comparison, but it was recorded with an aroma character of burnt food (aromagram peak number 27). An open source aroma database search narrows the possible identification of this compound from hundreds to six: octanol, indole, 3-methyl-1-butanol, ethyldimethylpyrazine, dimethyl sulfone, or furfuryl alcohol [17]. The use of olfactometry, by means of the human nose as a detector, is a very valuable tool for the identification of unknown compounds. The total aroma values, calculated as the sum of the area under the aromagram peaks, are compared in Figure 9 and no significant differences are exhibited between the seven Iowa red wines.

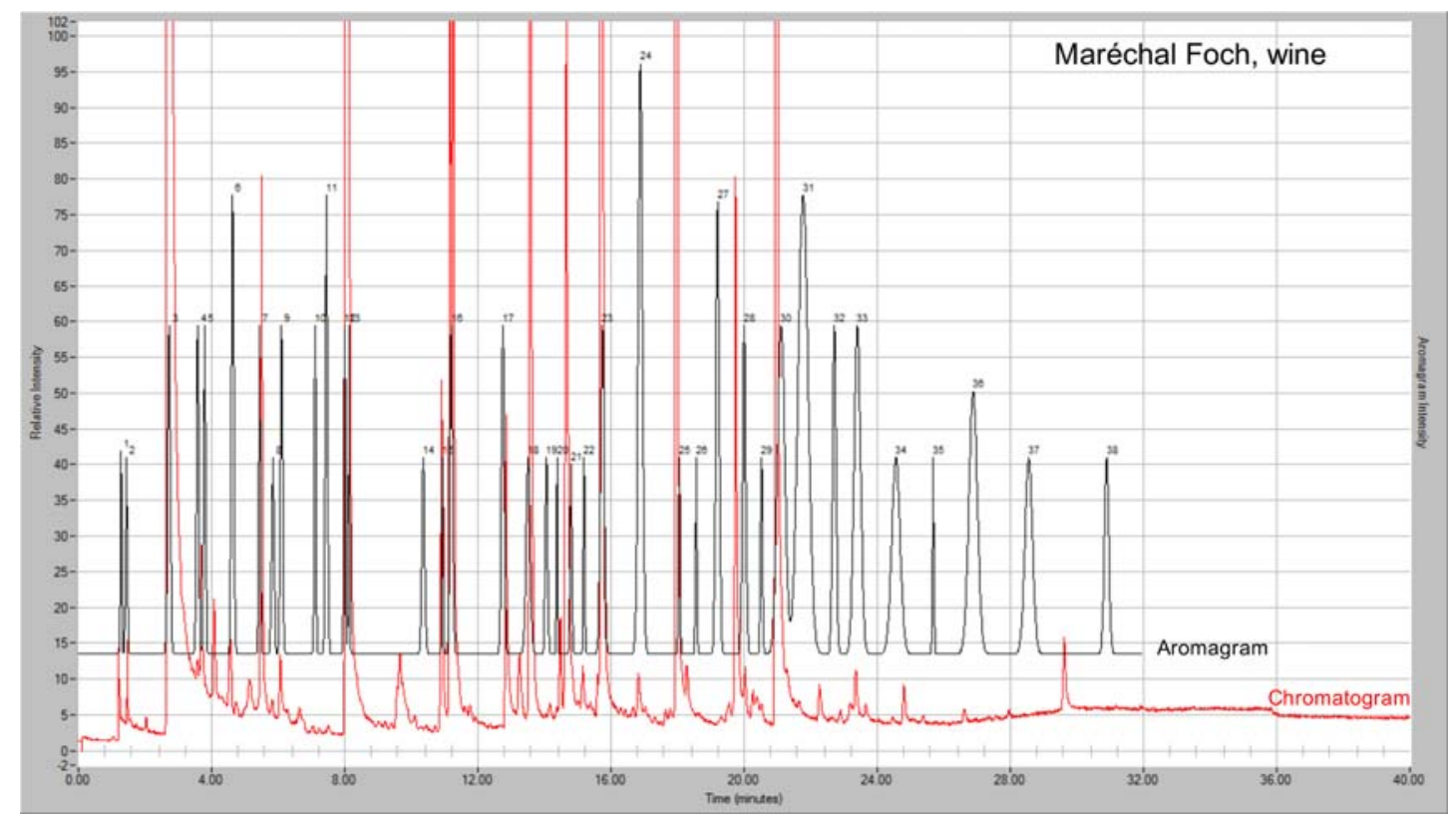

Figure 8. Overlay of total ion chromatogram and aromagram of an Iowa Maréchal Foch wine using the optimized method. Intense aromas (observed as increased peak height, black signal) and responsible chemical compounds (TIC, red signal) were aromagram peak: (\#6) sweet, fruity—ethyl isobutyrate (4.71 $\mathrm{min})$; (\#11) fruity—ethyl isovalerate (7.21 $\mathrm{min})$; (\#24) rancid, sweaty, body odor, burnt-isovaleric acid (16.83 $\mathrm{min}$ ) (\#27) burnt, burnt food-unknown compound (19 $\mathrm{min})$; (\#31) sweet, fruity, winey-ethyl laurate $(23.26 \mathrm{~min})$. Conditions: $2 \mathrm{~min}$ pre-sampling desorption of $50 / 30 \mu \mathrm{m} \mathrm{DVB} / C A R / P D M S$ SPME fiber; $4 \mathrm{~mL}$ wine sample in a $10 \mathrm{~mL}$ threaded glass amber vial with PTFE/silicone septa; $10 \mathrm{~min}$ incubation at $50{ }^{\circ} \mathrm{C} ; 10 \mathrm{~min}$ extraction time at $50{ }^{\circ} \mathrm{C}$; agitation speed $500 \mathrm{rpm} ; 2$ min desorption time into GC inlet. 


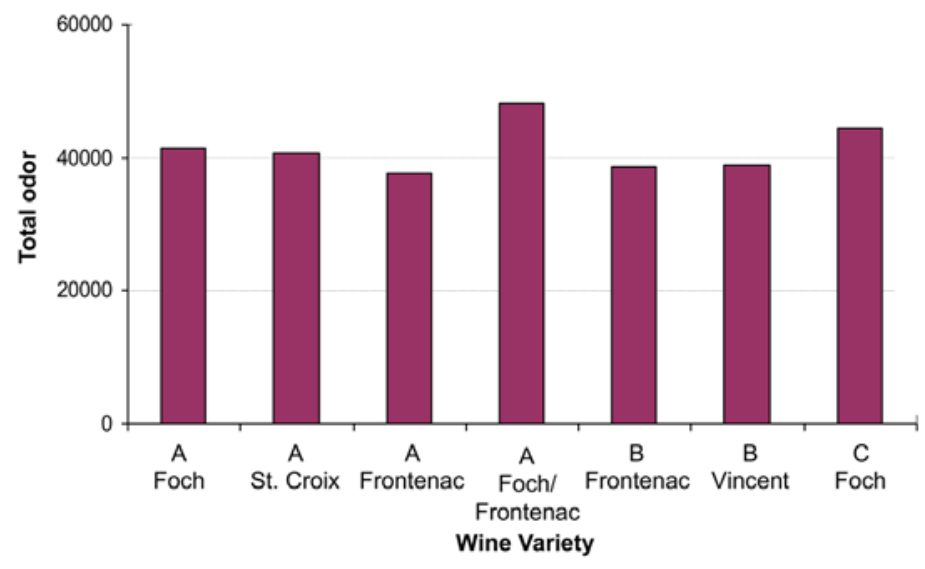

Figure 9. Overlay of total ion chromatogram and aromagram of an Iowa Maréchal Foch wine using the optimized method. Intense aromas (observed as increased peak height, black signal) and responsible chemical compounds (TIC, red signal) were aromagram peaks: (\#6) sweet, fruity—ethyl isobutyrate (4.71 $\mathrm{min})$; (\#11) fruity-ethyl isovalerate (7.21 min); (\#24) rancid, sweaty, body odor, burnt-isovaleric acid (16.83 $\mathrm{min}$ ) (\#27) burnt, burnt food-unknown compound (19 $\mathrm{min})$; (\#31) sweet, fruity, winey-ethyl laurate $(23.26 \mathrm{~min})$. Conditions: $2 \mathrm{~min}$ pre-sampling desorption of $50 / 30 \mu \mathrm{m}$ DVB/CAR/PDMS SPME fiber; $4 \mathrm{~mL}$ wine sample in a $10 \mathrm{~mL}$ threaded glass amber vial with PTFE/silicone septa; $10 \mathrm{~min}$ incubation at $50{ }^{\circ} \mathrm{C} ; 10 \mathrm{~min}$ extraction time at $50{ }^{\circ} \mathrm{C}$; agitation speed $500 \mathrm{rpm} ; 2$ min desorption time into GC inlet.

\section{Discussion}

The mixed adsorbent beds of the 50/30 $\mu \mathrm{m}$ DVB/CAR/PDMS coating were best suited for the extraction of wine volatiles, and extracted a greater mass of analytes than the other six fibers. The dual layer Car/PDMS/DVB fiber has been used to overcome the lack of selectivity toward some of the compounds in the single and double-phase fibers [18] and is consistent with previous work by Howard et al. [19]. Even though extraction equilibrium was not reached in some analytes (i.e., the profile is linear in shape at $10 \mathrm{~min}$ ), precision was assured by using the autosampler to control the mass transfer conditions. The addition of salt can improve the extraction efficiency up to a point, where the target analytes may interact with the salt ions in solution. These interactions will then reduce the extraction efficiency. This phenomenon has been shown to be related to the pKa of the analyte [20]. The total wine aroma is a balance between the heavier aroma of the alcohols, esters, acids, and the unpleasant rancid odors of the aliphatic acids and carbonyls which can be formed during the fermentation process. It should be noted that these 36 compounds were detected in the presence of a highly volatile organic solvent. In Figure 10, ethanol is present at 2.8-3.0 $\mathrm{min}$ and is the most abundant compound in the headspace of wine, as expected.

Four esters, including ethyl caproate, ethyl isobutyrate, ethyl isovalerate, and isoamyl acetate, were detected in seven Iowa red wines. In only one previous study, nonanal, (E,Z)-2,6-nonadienal, $\beta$-damascenone, ethyl caprylate, and isoamyl acetate had the highest OAVs in Frontenac, Marquette, Maréchal Foch, Sabrevois, and St. Croix wines, using SPME-GCMS(TOF) [21]. Ethyl caproate was previously reported in an analysis of Frontenac and Marquette juice from Quebec using SPME-GCMS [22]. Five compounds in selected Iowa red wines (i.e., isoamyl alcohol, ethyl caproate, benzeneethanol, ethyl decanoate, and ethyl caproate) were also found in Cabernet Sauvignon and Merlot, where ethyl caproate and ethyl caprylate were reported as the most abundant ethyl esters in these vinifera varieties [23]. These compounds have been attributed to yeast metabolism and do not impart any varietal characteristics to wine [24].

A principal components analysis followed by hierarchical clustering analysis is shown in Figure 11. St. Croix (from winery B) and Frontenac (from wineries B and D) are distinguishable by the grape variety and from the other five wine samples. Frontenac from winery B was more significantly 
associated with (31) octanoic acid than Frontenac from winery D. Maréchal Foch wines (from wineries B and D) were not similar to each other or when blended with Frontenac (from winery B). Maréchal Foch from winery B was associated (8) with ethyl isovalerate, Maréchal Foch from winery D was associated with (20) benzaldehyde, and Maréchal Foch/Frontenac blend from winery B was associated with (16) furfural. Vincent wine from winery $C$ and the Maréchal Foch/Frontenac blend from winery $\mathrm{B}$ were similar in wine aroma. It cannot be determined if the difference in aroma is due to the variety or winemaking practices for the Maréchal Foch, Maréchal Foch/Frontenac blend, or Vincent wines.

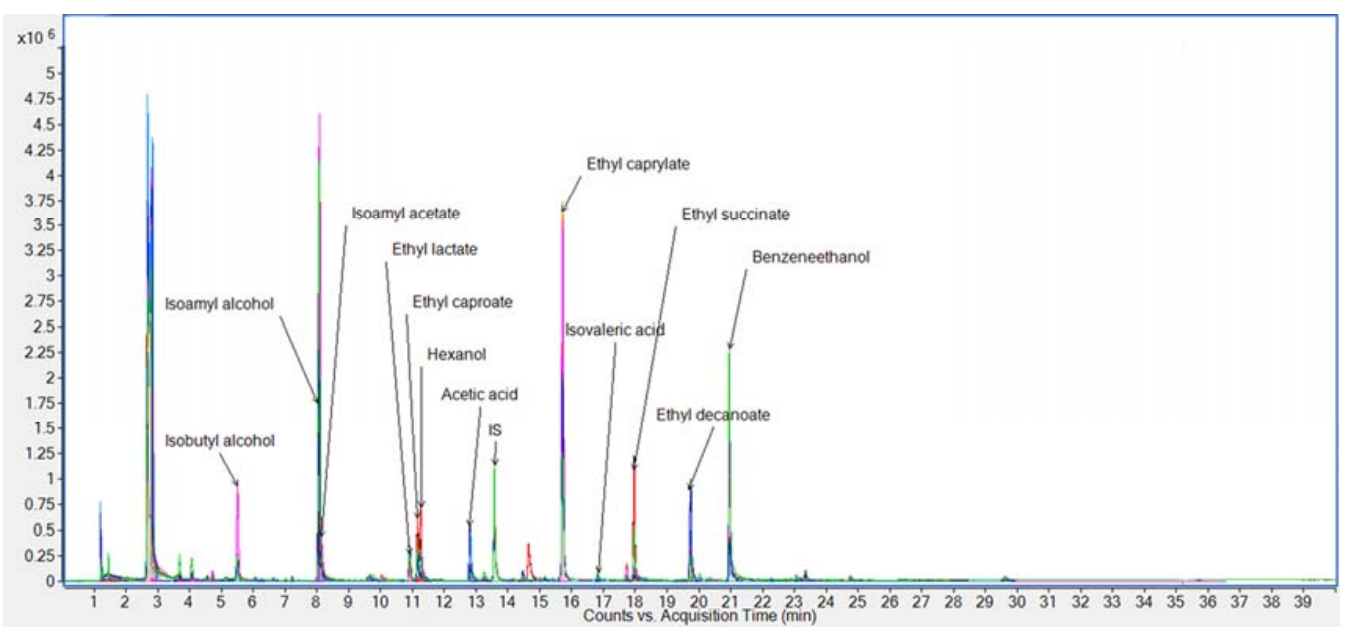

Figure 10. Overlay of total compound chromatograms of seven selected lowa red wines using the optimized method. Wines included: two bottles of Maréchal Foch, one bottle of St. Croix, two bottles of Frontenac, one bottle of Vincent, and one bottle of Maréchal Foch/Frontenac blend. Conditions: 2 min pre-sampling desorption of 50/30 $\mu \mathrm{m}$ DVB/CAR/PDMS SPME fiber; $4 \mathrm{~mL}$ wine sample in a $10 \mathrm{~mL}$ threaded glass amber vial with PTFE/silicone septa; $10 \mathrm{~min}$ incubation at $50{ }^{\circ} \mathrm{C} ; 10 \mathrm{~min}$ extraction time at $50{ }^{\circ} \mathrm{C}$; agitation speed $500 \mathrm{rpm} ; 2$ min desorption time into GC inlet.

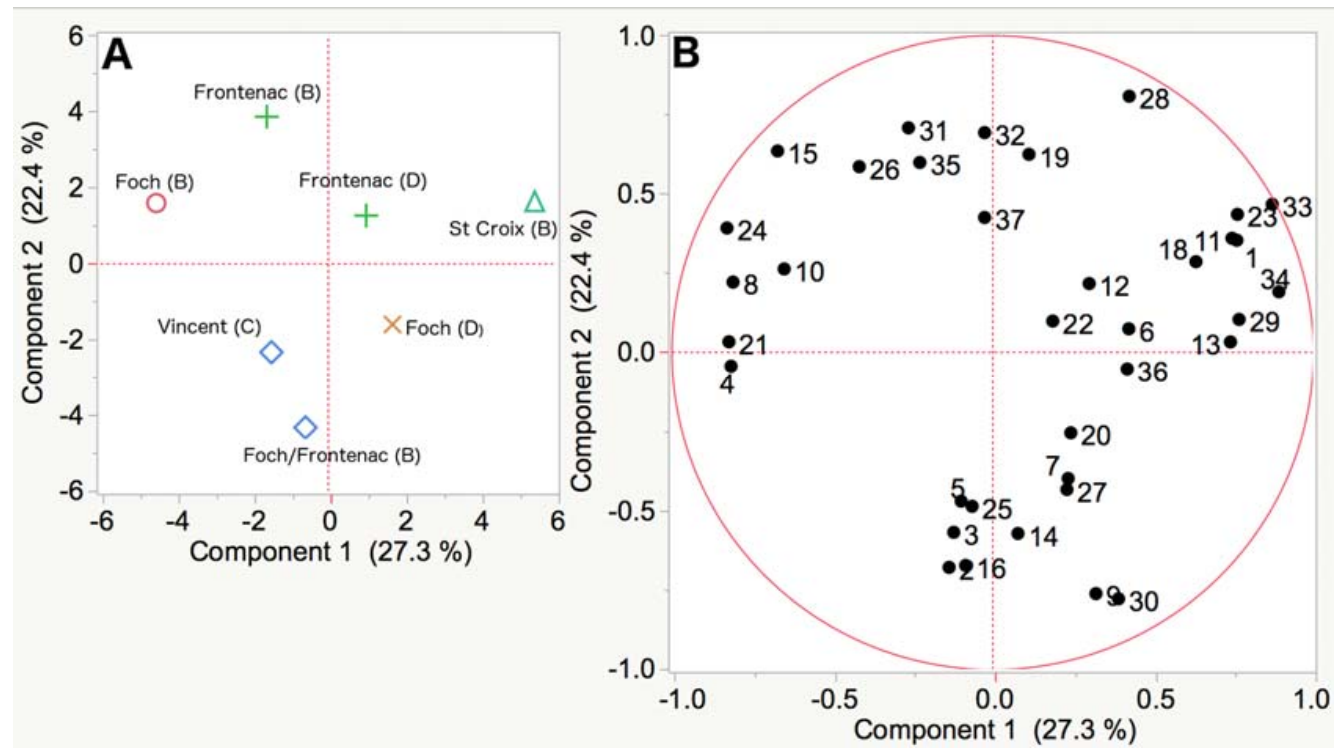

Figure 11. A principal components analysis of wine aroma of seven wines from three different Iowa wineries (A) and variables (B). Numbered variables refer to peak numbers in Table 2. Internal standard (17) 3-nonanone is not included in (B) because there was no variation between the samples. 
An automated headspace SPME method, coupled with GCMS-olfactometry was developed to characterize wine aroma. This method was applied to characterize 36 aroma compounds present in seven Iowa red wines from three different wineries. The interactions between the experimental factors were not considered in this research. A multivariate experimental design aimed to determine the main factors followed by a response surface methodology [25] could yield better results. Although a distinct varietal aroma character was not 'pinpointed' for these Iowa red wines, there were notable differences in the aroma profile by grape variety and by the winery. Linking aroma compounds to grape variety and winemaking practices continues to be important in producing high quality Iowa wines.

Acknowledgments: The authors acknowledge funding provided through the Iowa Department of Agricultural and Land Stewardship (07-1273; Project title: Development of a rapid screening method for chemical and aroma analyses of Iowa wines: transresveratrol and aroma-enhancing compounds).

Author Contributions: L.C., J.A.K., and M.D. conceived and designed the experiments; L.C. performed the experiments; L.C. and S.R. analyzed the data; J.A.K. and M.D. contributed reagents/materials/analysis tools; L.C., S.R., J.A.K., and D.M. wrote the paper.

Conflicts of Interest: The authors declare no conflict of interest. The funding sponsors had no role in the design of the study; in the collection, analyses, or interpretation of data; in the writing of the manuscript, and in the decision to publish the results.

\section{References}

1. Schreier, P.; Jennings, W.G. Flavor composition of wines: A review. CRC Crit. Rev. Food Sci. Nutr. 1979, 12, 59-111. [CrossRef] [PubMed]

2. Rapp, A. Wine aroma substances from gas chromatographic analysis. In Modern Methods of Plant Analysis; Linskens, H.F., Jackson, J.F., Eds.; Springer: Berlin, Germany, 1988; Volume 6, pp. 29-66. [CrossRef]

3. Sauvageot, F.; Vivier, P. Effects of malolactic fermentation on sensory properties of four burgundy wines. Am. J. Enol. Vitic. 1997, 48, 187-192.

4. De Revel, G.; Bertrand, A. Dicarbonyl compounds and their reduction products in wine. Identification of wine aldehydes. In Trends in Flavour Research; Maarse, H., van der Heij, D.G., Eds.; Elsevier Science B.V.: Amsterdam, The Netherlands, 1994; Volume 35, p. 353. ISBN 0444815872.

5. Allen, M. What level of methoxypyrazines is desired in red wines? The flavour perspective of the classic red wines of Bordeaux. Aust. Grapegrow. Winemak. 1995, 381, 7-9.

6. Davis, C.R.; Wibowo, D.; Eschenbruch, R.; Lee, T.H.; Fleet, G.H. Practical implications of malolactic fermentation: A review. Am. J. Enol. Vitic. 1985, 36, 290-301.

7. Rapp, A.; Güntert, M.; Almy, J. Identification and significance of several sulfur-containing compounds in wine. Am. J. Enol. Vitic. 1985, 36, 219-221.

8. Montedoro, G.; Bertuccioli, M. The flavour of wines, vermouth and fortified wines. In Food flavours, Part B, The Flavour of Beverages; Morton, I.D., MacLeod, A.J., Eds.; Elsevier Science Ltd.: Amsterdam, The Netherlands, 1986; p. 171. ISBN 9780444425997.

9. Rapp, A.; Versini, G. Methylanthranilate ("foxy taint") concentrations of hybrid and Vitis vinifera wines. Vitis 1996, 35, 215-216.

10. Margalit, Y. Concepts in Wine Chemistry, 3rd ed.; The Wine Appreciation Guild: San Francisco, CA, USA, 2012; p. 203. ISBN 1-935879-94-4.

11. Fuller, G.H.; Steltenkamp, R.; Tisserand, G.A. The gas chromatograph with human sensor: Perfumer model. Ann. N. Y. Acad. Sci. 1964, 116, 711-724. [CrossRef] [PubMed]

12. Robinson, A.L.; Boss, P.K.; Solomon, P.S.; Trengrove, R.D.; Heymann, H.; Ebeler, S.E. Origins of grape and wine aroma. Part 2. Chemical and sensory analysis. Am. J. Enol. Vitic. 2014, 65, 25-42. [CrossRef]

13. Panighel, A.; Flamini, R. Solid phase extraction and solid phase microextraction in grape and wine volatile compounds analysis. Sample Prep. 2015, 2, 55-65. [CrossRef]

14. Pawliszyn, J. Handbook of Solid Phase Microextraction; Chemical Industry Press: Beijing, China, 2009; pp. 90-103. ISBN 978-7-122-04701-4. 
15. Zhang, S.; Koziel, J.A.; Cai, L.; Hoff, S.J.; Heathcote, K.Y.; Chen, L.; Jacobson, L.D.; Akdeniz, N.; Hetchler, B.P.; Parker, D.B.; et al. Odor and odorous chemical emissions from animal buildings: Part 5. Simultaneous chemical and sensory analysis with gas chromatography-mass spectrometry-olfactometry. Trans. ASABE 2015, 58, 1349-1359. [CrossRef]

16. LRI \& Odour Database. Available online: http://www.webcitation.org/6rDRATLKY (accessed on 14 June 2017).

17. Flavornet and Human Odor Space. Available online: http://www.webcitation.org/6qr4xTprN (accessed on 30 May 2017).

18. Ferreira, A.C.S.; de Pinho, P.G. Analytical method for determination of some aroma compounds on white wines by solid phase microextraction and gas chromatography. J. Food Sci. 2003, 68, 2817-2820. [CrossRef]

19. Howard, K.L.; Mike, J.H.; Riesen, R. Validation of a solid-phase microextraction method for headspace analysis of wine aroma compounds. Am. J. Enol. Vitic. 2005, 56, 37-45.

20. Hall, B.J.; Brodbelt, J.S. Determination of barbiturates by solid-phase microextraction (SPME) and ion trap gas chromatography-mass spectrometry. J. Chromatogr. A 1997, 777, 275-282. [CrossRef]

21. Slegers, A.; Angers, P.; Ouellet, E.; Truchon, T.; Pedneault, K. Volatile compounds from grape skin, juice, and wine from five interspecific hybrid grape cultivars grown in Quebec (Canada) for wine production. Molecules 2015, 20, 10980-11016. [CrossRef] [PubMed]

22. Pedneault, K.; Martine, D.; Angers, P. Flavor of cold-hardy grapes: Impact of berry maturity and environmental conditions. J. Agric. Food Chem. 2013, 61, 10418-10438. [CrossRef] [PubMed]

23. Cheng, G.; Liu, Y.; Yue, T.X.; Zhang, Z.W. Comparison between aroma compounds in wines from four Vitis vinifera grape varieties grown in different shoot positions. Food Sci. Technol. Camp. 2015, 35, 237-246. [CrossRef]

24. Jackson, R.S. Wine Science Principles and Applications, 3rd ed.; Elsevier: Amsterdam, The Netherlands, 2008; p. 662. ISBN 978-0-12-373646-8.

25. Gunst, R.F. Response surface methodology: Process and product optimization using designed experiments. Technometrics 1996, 38, 284-286. [CrossRef] 